\title{
Application Value of Blood Types Gene Detection in Blood Transfusion of Patients with ABO Blood Type Identification Difficulty
}

\author{
YUN TANG XU, X. X. KONG ${ }^{1}$, C. W. WANG, YAN HU AND J. GU1*
}

Department of Blood Transfusion, '1Department of Laboratory, Lianyungang Hospital of Traditional Chinese Medicine, No. 160, Chaoyang Middle Road, Lianyungang, Jiangsu 222001, China

\section{Xu et al.: Application Value of Blood Types Gene Detection}

\begin{abstract}
The human red blood cell blood group system plays an extremely important role in blood transfusion medicine and the ABO blood group system is of great significance in clinical blood transfusion, organ transplantation, forensic medicine and genetics research. The aim of this study was to study the application of genotyping technology in difficult ABO blood types identification. A total of 12 patients were selected in our hospital from August 2019 to August 2020. Among them, 1 patient with peptic ulcer, 1 patient with chronic kidney disease stage V, 2 patients with diabetes, 1 patient with infertility, 3 patients with anemia, 1 patient with primary liver cancer, 2 patients with leukemia and 1 patient with systemic lupus erythematosus. Polymerase chain reaction-sequence specific primers genotyping method was used to detect these patients with difficult $\mathrm{ABO}$ blood type antigens and statistical method was used to analyze the correlation of $\mathrm{ABO}$ genotypes and difficult $\mathrm{ABO}$ blood types. The specific distribution of $\mathrm{ABO}$ genotypes in 12 patients were detected as follows: 6 cases of $A / B, 3$ cases of $A / O$ and 3 cases of $B / O$. The genotype detected by polymerase chain reaction-sequence specific primers was consistent with serological phenotype. As an auxiliary method, $\mathrm{ABO}$ genotyping can be used to detect difficult $\mathrm{ABO}$ blood types.
\end{abstract}

Key words: Genotyping technique, ABO genotyping, polymerase chain reaction-sequence specific primers, blood group serology

The blood group system of human red blood cells plays an important role in blood transfusion medicine. At present, 36 human erythrocyte blood group systems have been detected, among which ABO blood group system is the earliest and most important one ${ }^{[1]}$. It is of great significance in clinical blood transfusion, organ transplantation, forensic medicine and genetics research $^{[2,3]}$. ABO blood groups in addition to the most common $\mathrm{A}, \mathrm{B}, \mathrm{O}$ and $\mathrm{AB}$ types, there are also some subtypes, such as $A_{2}, A_{3}, A_{m}, A_{x}, A E L$, aAnt, $B_{3}, B_{m}, B_{x}$, CisAB, B (A), etc. ${ }^{[4]}$. The serological manifestations of these subtypes are often inconsistent, which brings great difficulties to clinical blood group identification and cross matching. Serological detection can fully understand the situation of $\mathrm{ABO}$ antigen and antibody, but the analysis of the causes of the positive and negative stereotypes in the detection is easily affected by a variety of factors, such as disease status, recent blood transfusion history, lack of pedigree, unable to analyze heredity, etc. However, gene detection can make up for the shortage of serological detection and provide a new detection method for the samples with difficult serological identification. In recent years, the continuous development of deoxyribonucleic acid (DNA) molecular detection technology provides a new possibility for the accurate identification of these difficult ABO blood group samples ${ }^{[5,6]}$. Therefore, the stable polymerase chain reaction-sequence specific primers (PCR-SSP) technology was used to determine the $\mathrm{ABO}$ genotypes of difficult $\mathrm{ABO}$ blood group samples in our hospital and the identification of 12 difficult ABO blood group samples was solved. From August 2019 to August 2020, 12 blood samples of clinical patients from various departments of our hospital were selected and all of them were anticoagulated with dipotassium ethylenediamine tetraacetic acid (K2-EDTA). Serological typing of blood samples by routine serological techniques was

*Address for correspondence

E-mail: Ilah2365@sina.com 
carried out. The anti-A antibody, anti-O antibody, anti-B antibody, anti $\mathrm{AB}$ antibody and anti-H antibody used in all blood samples were prepared by the same company and the $\mathrm{ABO}$ reagent used for detection was prepared by our hospital. DNA extraction was carried out. The target gene was extracted from $5 \mathrm{ml}$ whole blood of 12 patients anti-coagulated with K2-EDTA by guanidine hydrochloride/protease K cleavage extraction method and about $300 \mu$ DNA was finally obtained. Specific primers were designed according to $\mathrm{ABO}$ nucleotide sequence and human growth hormone (HGH) was used as internal control gene. PCR amplification: $1 \mu \mathrm{l}$ of extracted target gene, $1 \mu \mathrm{l}$ of Taq polymerase (DNA polymerase) purchased by Promega company and $7 \mu$ of human leukocyte antigen (HLA) genotyping primers produced by sigma company mixed with specific primers, deoxynucleotide triphosphates (dNTPs), buffer and internal control primers were used under hot start technology. The total volume of PCR reaction was $9 \mu \mathrm{l}$. The PCR reaction was carried out at $95^{\circ}$ for $5 \mathrm{~min}$. After preheat, denatured at $95^{\circ}$ for $30 \mathrm{~s}$, annealed at $60^{\circ}$ for $30 \mathrm{~s}$ and extended at $72^{\circ}$ for 1.5 $\min$. The above operation process was cycled for 30 times, extended at $72^{\circ}$ for $5 \mathrm{~min}$ and finally cooled to $4^{\circ}$. The sequence is shown in Table 1 . All the primers were prepared in the kit of $\mathrm{G} \& \mathrm{~T}$ Company. Gel electrophoresis of the final products obtained from PCR was carried out using $2 \%$ agarose gel prepared from the same buffer. After ethidium bromide (EB) staining, 20 min electrophoresis was performed at $100 \mathrm{~V}$ voltage and the electrophoresis results were recorded under ultraviolet lamp. The inner control band appeared under ultraviolet (UV) transmission, indicating that PCR amplification was successful. The results of electrophoresis showed that those with specific amplification products were positive. The serological phenotypes of 12 clinical patients included 3 cases of $\mathrm{AB}, 2$ cases of $\mathrm{O}, 3$ cases of A and 4 cases of $\mathrm{B}$. Analysis of serological phenotype in 12 clinical patients was shown in Table 2 . The genotypes of 12 patients were $\mathrm{A} / \mathrm{B}$ in $6, \mathrm{~A} / \mathrm{O}$ in 3 and $\mathrm{B} / \mathrm{O}$ in 3 . The genotypes detected by PCR-SSP were consistent with serological phenotypes, as shown in Table 3. There are many kinds of antigens on the surface of human red blood cells, which are classified and combined by alloantigens, namely blood group system. There are more than 80 known blood group systems, including $\mathrm{ABO}$, MNS, $\mathrm{P}$, Rhesus (Rh), Lutheran, Kell, Lewis, Duffy, Kidd, Hh/ Bombay, etc. These systems exist independently and the genes controlling the inheritance of all blood group systems are located on the same chromosome ${ }^{[7,8]}$. The most important blood group system in clinic is $\mathrm{ABO}$ system and $\mathrm{Rh}$ system. $\mathrm{ABO}$ system also has a variety of phenotypes and subtypes. ABO genetic gene is located in 9q34.1-9q34.2, with high homology, only a single base or several base substitutions. It is a highly conserved nucleotide sequence and its molecular basis is that highly homologous glycogen interacts with $\mathrm{H}$ under the action of galactosyltransferase. The precursor is formed by the linkage of galactose. Studies have shown that the identification of serological ABO subtypes is unreliable. Although there are many reports of $\mathrm{ABO}$ system subtypes in China, these reports often lack the experimental results of nucleotide mutation and the serological detection is affected by different monoclonal antibodies, different reagent specificity, antigen gene change, different laboratory detection conditions and even different operator operation ${ }^{[9,10]}$. We think that the blood samples with irregular reaction of antigen and antibody should be further genotyped and the experimental results should be used as a reliable basis for subtype diagnosis. For the units with poor experimental qualification, such blood samples should be sent to the regional or national reference laboratory for further confirmation, so as to prevent misdiagnosis. Since anti-A, anti-B and anti AB antibodies naturally exist in human serum, even if only a few milliliters of mismatched blood are injected, it can cause serious hemolytic reaction and even cause serious consequences of patient death ${ }^{[1-13]}$. Therefore, it is very important to determine $\mathrm{ABO}$ blood group in clinical practice. In this study, stable PCR-SSP method was used to identify ABO blood group subtypes accurately, which can exclude the errors caused by autoantibodies or irregular antibodies and also excludes the changes of ABO blood group subtypes caused by leukemia, myelodysplastic syndrome and other tumors. In addition, PCR-SSP method is not interfered by bacteria and hemoglobin disorder and has low requirements for samples. All nucleated cells can be used as experimental samples, including skin follicles, blood stains, amniotic fluid, tissue blocks, seminal spots, etc. qualified experimental results can be obtained by PCR amplification. At the same time, PCR-SSP technology is easy to obtain, preserve and transport samples and the results of experiments in different laboratories are comparable, which can make up for the lack of conventional serological detection. Different from conventional serological detection, which can only identify the phenotype of blood samples, PCR-SSP technology can accurately identify blood group subtypes, heterozygotes and homozygotes, which is of great significance for 
difficult to identify subtypes and prenatal fetal blood group diagnosis and its wide range of materials also enables it to play a role in forensic identification, genetic identification, etc. ${ }^{[14-16]}$. The results of this study showed that the serological phenotypes of 12 clinical patients included 3 cases of $\mathrm{AB}, 2$ cases of $\mathrm{O}, 3$ cases of $A$ and 4 cases of $B$. The genotypes of 12 patients were detected by PCR-SSP, including 6 cases of A/B, 3 cases of $\mathrm{A} / \mathrm{O}$ and 3 cases of $\mathrm{B} / \mathrm{O}$. The genotype detected by PCR-SSP was consistent with serological phenotype. Accurate identification of $\mathrm{ABO}$ blood group is the key to clinical safe blood transfusion ${ }^{[17]}$. If blood group identification is wrong, it may cause serious transfusion reaction and even lead to the death of patients. If the clinically difficult $\mathrm{ABO}$ blood group cannot be distinguished by serological means, it must be identified by molecular biological detection ${ }^{[18]}$. Molecular biology detection can significantly reduce the false detection rate of $\mathrm{ABO}$ blood group identification, which is of great significance for guiding clinical blood transfusion and more effective use of rare blood group resources and also provides the basis for individualized precision blood transfusion ${ }^{[19]}$, further making clinical blood use accurate, reasonable and efficient.

\section{TABLE 1: PRIMER SEQUENCES}

\begin{tabular}{lcc}
\hline Gene & F & R \\
\hline HGH & 5'-GGCCTTCCCAACCATTCCCTTA-3' & 5'-CTCACGGATTTCTGTTGTGTTTC-3' \\
Mix-15i & 5'-AGGAAGGATGTCCTCGTGGTA-3' & 5'-GGCCCACGTGGTCGCGGAAC-3' \\
Mix-25i & 5'-GGAAGGATGTGCTCGT-GGTGA-3' & 5'-GCCCCGAAGAACCCCCCCAG-3' \\
Mix-35i & 5'-GGAAGGATGTGCTCGTGGTGA- 3' & 5'-GGCCCACGTGGTCGCGGATC-3' \\
Mix- $45 i$ & 5'-AGGAAGGATGTCCTCGTGGTA-3' & 5' -GGCCCACGTGGTCGCGGATC-3' \\
Mix-55i & 5'-GGAAGGATGTGCTCGTGGTGA-3' & 5'-GCCCCGAAGAACGCCCCCAT-3' \\
Mix-65i & 5'-GGAAGGATGTGCTCGTGGTGA-3' & 5'-GTGCTTCCG-TAGAAGCTGGG-3' \\
\hline
\end{tabular}

TABLE 2: ANALYSIS OF SEROLOGICAL PHENOTYPE IN 12 CLINICAL PATIENTS

\begin{tabular}{lcc}
\hline Number & Source of specimen & Serological phenotype \\
\hline 1 & Peptic ulcer & $\mathrm{AB}$ \\
2 & Chronic kidney disease stage 5 & 0 \\
3 & Diabetes & $\mathrm{A}$ \\
4 & Infertility & $\mathrm{B}$ \\
5 & Diabetes & $\mathrm{AB}$ \\
6 & Anemia & $\mathrm{B}$ \\
7 & Anemia & $\mathrm{B}$ \\
8 & Primary liver cancer & $\mathrm{C}$ \\
9 & Anemia & $\mathrm{A}$ \\
10 & Leukemia & $\mathrm{AB}$ \\
11 & Systemic lupus erythematosus & $\mathrm{A}$ \\
12 & Leukemia & $\mathrm{B}$ \\
\hline
\end{tabular}

TABLE 3: ANALYSIS OF GENOTYPES AND PCR RESULTS IN 12 PATIENTS

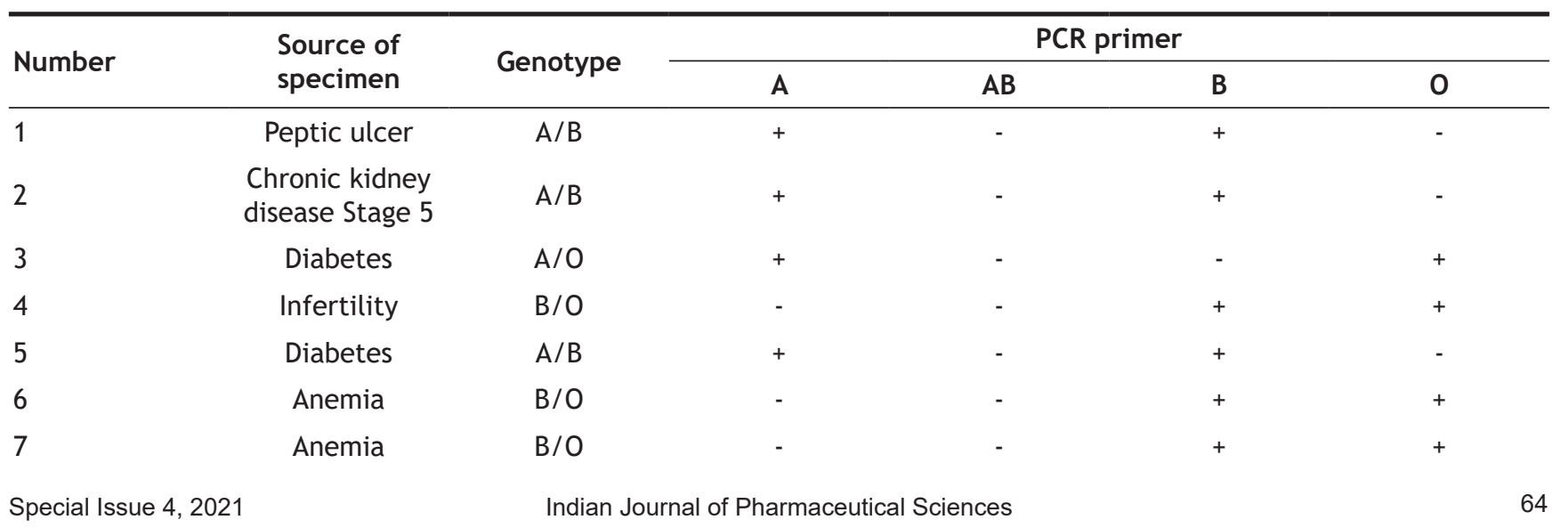


www.ijpsonline.com

\begin{tabular}{|c|c|c|c|c|c|c|}
\hline 8 & $\begin{array}{c}\text { Primary liver } \\
\text { cancer }\end{array}$ & $A / B$ & + & - & + & - \\
\hline 9 & Anemia & $\mathrm{A} / \mathrm{O}$ & + & - & - & + \\
\hline 10 & Leukemia & $A / B$ & + & - & + & - \\
\hline 11 & $\begin{array}{l}\text { Systemic lupus } \\
\text { erythematosus }\end{array}$ & $\mathrm{A} / \mathrm{O}$ & + & - & - & + \\
\hline 12 & Leukemia & $\mathrm{A} / \mathrm{B}$ & + & - & + & - \\
\hline
\end{tabular}

\section{Acknowledgements:}

This work was supported by the Lianyungang Hospital of Traditional Chinese Medicine.

\section{Conflicts of interest:}

The authors report no conflicts of interest.

\section{REFERENCES}

1. Huang H, Jin S, Liu X, Wang Z, Lu Q, Fan L, et al. Molecular genetic analysis of weak ABO subgroups in the Chinese population reveals ten novel ABO subgroup alleles. Blood Transfus 2019;17(3):217-22.

2. Morgan WT, Watkins WM. Unravelling the biochemical basis of blood group $\mathrm{ABO}$ and Lewis antigenic specificity. Glycoconj J 2000;17(7):501-30.

3. Bennett EP, Steffensen R, Clausen H, Weghuis DO, Vankessel AG. Genomic cloning of the human histo-blood group ABO locus. Biochem Biophys Res Commun 1995;206(1):318-25.

4. Yamamoto FI, Clausen H, White T, Marken J, Hakomori SI. Molecular genetic basis of the histo-blood group ABO system. Nature 1990;345(6272):229-33.

5. Patenaude SI, Seto NO, Borisova SN, Szpacenko A, Marcus SL, Palcic MM, et al. The structural basis for specificity in human ABO $(\mathrm{H})$ blood group biosynthesis. Nat Struct Biol 2002;9(9):685-90.

6. Hosseini-Maaf B, Letts JA, Persson M, Smart E, LePennec PY, Hustinx H, et al. Structural basis for red cell phenotypic changes in newly identified, naturally occurring subgroup mutants of the human blood group B glycosyltransferase. Transfusion 2007;47(5):864-75.

7. Seltsam A, Gruger D, Just B, Figueiredo C, Gupta CD, DeLuca $\mathrm{DS}$, et al. Aberrant intracellular trafficking of a variant $\mathrm{B}$ glycosyltransferase. Transfusion 2008;48(9):1898-905.

8. Hult AK, Yazer MH, Jorgensen R, Hellberg A, Hustinx H, Peyrard $\mathrm{T}$, et al. Weak A phenotypes associated with novel ABO alleles carrying the A2-related $1061 \mathrm{C}$ deletion and various missense substitutions. Transfusion 2010;50(7):147186.

9. Cai X, Jin S, Liu X, Fan L, Lu Q, Wang J, et al. Molecular genetic analysis of ABO blood group variations reveals 29 novel ABO subgroup alleles. Transfusion 2013;53:2910-6.
10. Sano R, Nakajima T, Takahashi K, Kubo R, Kominato Y, Tsukada $\mathrm{J}$, et al. Expression of $\mathrm{ABO}$ blood-group genes is dependent upon an erythroid cell-specific regulatory element that is deleted in persons with the Bm phenotype. Blood 2012;119(22):5301-10.

11. Cai X, Qian C, Wu W, Lei H, Ding Q, Zou W, et al. An exonic missense mutation c. $28 \mathrm{G}>\mathrm{A}$ is associated with weak B blood group by affecting RNA splicing of the ABO gene. Transfusion 2017;57(9):2140-9.

12. Cai XH, Jin S, Liu X, Shen W, Lu Q, Wang JL, et al. Molecular genetic analysis for the $\mathrm{Bx}$ subgroup revealing two novel alleles in the ABO gene. Transfusion 2008;48(11):2442-7.

13. Pettersen EF, Goddard TD, Huang CC, Couch GS, Greenblatt DM, Meng EC, et al. UCSF Chimera-a visualization system for exploratory research and analysis. J Comput Chem 2004;25(13):1605-12.

14. de Baets G, Van Durme J, Reumers J, Maurer-Stroh S, Vanhee P, Dopazo J, et al. SNP effect 4.0: On-line prediction of molecular and structural effects of protein-coding variants. Nucleic Acids Res 2012;40:D935-9.

15. Humphrey W, Dalke A, Schulten K. VMD: Visual molecular dynamics. J Mol Graph 1996;14(1):33-8.

16. Cho D, Shin DJ, Yazer MH, Ihm CH, Hur YM, Kee SJ, et al. The M142T mutation causes B3 phenotype: three cases and an in vitro expression study. Korean J Lab Med 2010;30(1):65-9.

17. Guerois R, Nielsen JE, Serrano L. Predicting changes in the stability of proteins and protein complexes: A study of more than 1000 mutations. J Mol Biol 2002;320(2):369-87.

18. Cho D, Kim SH, Ki CS, Choi KL, Cho YG, Song JW, et al. A novel Bvar allele (547 G>A) demonstrates differential expression depending on the co-inherited ABO allele. Vox Sang 2004;87(3):187-9.

19. Chen YJ, Chen PS, Liu HM, Lyou JY, Hu HY, Lin JS, et al. Novel polymorphisms in exons 6 and 7 of A/B alleles detected by polymerase chain reaction-single strand conformation polymorphism. Vox Sang 2006;90(2):119-27.

This is an open access article distributed under the terms of the Creative Commons Attribution-NonCommercial-ShareAlike 3.0 License, which allows others to remix, tweak, and build upon the work non-commercially, as long as the author is credited and the new creations are licensed under the identical terms

This article was originally published in a special issue,

"Therapeutic Perspectives in Biomedical Research and Pharmaceutical Sciences and their Nursing Methods"

Indian J Pharm Sci 2021:83(4)Spl issue "62-65" 